\title{
Desenvolvimento regional e cooperação entre empresas - instituições: o caso dos arranjos produtivos locais de tecnologia da informação do Paraná
}

\author{
Paulo Cruz Correia - correiapc@yahoo.com.br \\ UNESPAR - Universidade Estadual do Paraná \\ Noelia Felipe - noeliafelipe@ uol.com.br \\ UNESPAR - Universidade Estadual do Paraná \\ Tânia Terezinha Rissa de Souza - tania.rissa@unespar.edu.br \\ UNESPAR - Universidade Estadual do Paraná \\ Paula Tissiany Viana de Macêdo Carneiro - paula_eco@yahoo.com.br \\ UNESPAR - Universidade Estadual do Paraná \\ Aylton Paulus Júnior - aylton.paulus@ unespar.br \\ UNESPAR - Universidade Estadual do Paraná
}

\begin{abstract}
Resumo: Este trabalho avalia as aglomerações produtivas de Tecnologia da Informação das Regiões Metropolitanas de Curitiba, Londrina e Maringá, seguindo as especificidades do SNI - Sistema Nacional de Inovação - em sua abordagem em nível mesoeconômico. Analisam-se as relações de cooperação entre as firmas, com organizações e instituições e, conjuntamente, a compradoresfornecedores e a formação de suas competências técnicas por meio das relações com entidades e associações de apoio e coordenação. Conclui-se que essas relações tendem a gerar externalidades positivas entre firmas-regiões (economias externas), tanto incidentais (inconscientemente) quanto planejadas (buscadas pelas firmas), as quais ocorrem por força da proximidade geográfica ou de suas especializações setoriais.
\end{abstract}

Palavras-chave: Aglomerações produtivas, Cooperação, instituições-empresas.

\begin{abstract}
In this paper, we evaluate the productive agglomerations of Information Technology in the Metropolitan areas of Curitiba, Londrina, and Maringá, following the peculiarities of the NSI (National System of Innovation) in its approach to the meso economic level. Cooperative relations between companies were analyzed, taking into account organizations and institutions along with supplier-buyers, and the formation of their technical capabilities through relations with support \& coordination entities and associations. We conclude that these relations tend to generate positive externalities between region-companies (external economies), both incidental (unconscious) and planned (forged by these companies), which happen due to the geographical closeness of their industrial specializations.
\end{abstract}

Keywords: Productive agglomerations, Institutions-companies, cooperation. 


\section{Introdução}

Atualmente, as Regiões Metropolitanas de Curitiba, Londrina e Maringá (PR) vêm se destacando nas atividades de Tecnologia da Informação (TI), ao alcançarem significativos níveis de produção e qualidade, comparando-se com as demais firmas do Paraná nessa indústria. Tal atividade confere às regiões significativa participação na renda e geração de empregos. Essa indústria reúne uma característica de aglomeração produtiva local em fase de expansão a qual, por esse motivo, constitui-se em motivação de análise para as Regiões Metropolitanas de Curitiba (RMC), Londrina (RML) e Maringá (RMM) (ASSESPRO/PR, 2013).

Neste trabalho, por meio dos resultados da pesquisa de campo ${ }^{1}$, identificam-se e analisam-se, em nível mesoeconômico, acoplamentos específicos que relacionam fornecedores-produtores e consumidores com interação, governança e inovação entre organizações e instituições de apoio e coordenação, verificando competências e desempenhos. O texto está dividido em três seções. A segunda seção apresenta brevemente a abordagem teórico-metodológica, destacando os aspectos das aglomerações produtivas ou clusters (arranjos produtivos) industriais e inovações. A terceira seção apresenta os procedimentos metodológicos. A quarta seção mostra os resultados e discussões, incluindo a configuração das aglomerações produtivas, as ligações de cooperação entre firmas para a promoção da inovação e as relações de cooperação entre firmas e instituições na aglomeração produtiva de Tecnologia da Informação da RMC, RML e RMM. Por fim, são apresentadas algumas considerações finais e desafios.

\section{Aglomerações Produtivas}

Marshall foi quem primeiro identificou os benefícios das aglomerações industriais para o desenvolvimento empresarial (BECATTINI, 1994; MARSHALL, 1996). Muitas são as características de uma aglomeração empresarial em formação ou consolidada, entre elas a proximidade dos agentes atuando em cooperação, a coordenação que colocam os agentes em ação para realizações e benefícios conjuntos e a predominância, em larga medida, de empresas de micro, pequeno e médio porte. Entretanto, também existe competição em relação a esses agentes em atividades consideradas précompetitivas, mas as empresas se unem por meio de uma coordenação regional, local ou setorial para buscar benefícios por meio de ações políticas - emanadas pelas forças de instituições de apoio - junto aos poderes diversos, com vistas a buscar benefícios em favor de todos da aglomeração produtiva (GAROFOLI, 1994; SCHMITZ, 1997; EDQUIST, 1997; CAMPOS, 2004).

Ganha importância a dimensão territorial, pois é onde os agentes se organizam em diversos processos de cooperação para contínua busca da inovação. Essa organização permite aos agentes reduzirem custos e se articularem na inter-relação dos fluxos de produção. Com o amadurecimento das aglomerações produtivas - que podem se formar de formas incidentais ou planejadas - colocam-se frente a frente ainda uma diversidade de atores locais ou setoriais se inter-relacionando por meio do fornecimento de insumos e matérias primas, a montante e à jusante, fluxos que estão a todo o momento se ajustando. Por outro lado, também impõe novas configurações às rotinas e relações dos agentes envolvidos, com externalidades positivas entre as empresas das aglomerações produtivas (EDQUIST, 1997; BIANCHI e TOMMASO, 1998).

\section{Procedimentos metodológicos}

O sistema de Vetor de Capacitação Tecnológica (VCT) é um modelo de análise que separa as firmas em um foco de três níveis, sendo eles: o nível micro, o nível meso e o nível macro (CIMOLI e DELLAGIUSTA, 1988). No nível micro, analisa-se a firma do ponto de vista da inovação internamente, com suas melhorias organizacionais contínuas; no nível meso, analisa-se a firma em relação às suas inter-relações com sua rede de firmas parceira, além das instituições setoriais de sua

\footnotetext{
${ }^{1}$ A pesquisa de campo foi realizada entre 23 de setembro de 2012 e 14 de abril de 2013 nas empresas da aglomeração produtiva de TI da RMC, RML e RMM. Objetivou verificar os diversos aspectos que dão conformação a uma aglomeração produtiva especializada, consolidada, tais como: governança, cooperação, inovação e interação entre agentes, bem como suas relações com instituições públicas, em seus diversos níveis de análise e, de apoio e coordenação, como: sindicatos, associações comerciais, instituições de ensino e pesquisa, além de empresariais, como a FIEP e a ASSESPRO/PR.
} 
indústria, em termos locais, regionais e supranacionais. Por meio desse nível de análise é possível identificar os avanços da firma e seu aprendizado em seus aspectos de competição, além da interação entre a firma e rede de firmas e entre as firmas e suas entidades setoriais de coordenação e cooperação públicas e privadas. No nível macro, analisa-se a firma, ou sua rede de firmas, em relação ao conjunto político e social que lhe dá suporte. Assim, percebe-se a firma envolta em um conjunto de políticas que lhes afetam, como cambiais, tributárias e monetárias, e amparadas pelas organizações sociais de seu setor que lhes dão suporte (CIMOLI e DELLAGIUSTA, 1988).

A fim de melhor compreender o perfil das 60 empresas dessas aglomerações produtivas de TI, presentes na RMC, RML e RMM pesquisadas, de uma população de 1055, foram agrupadas de acordo com a classificação SEBRAE ${ }^{2}$. Essas regiões, entretanto, as quais alcançaram escala e dimensão importantes no desenvolvimento econômico regional, tomadas como objeto de estudo para este trabalho, assumem relevante importância, conforme apresentado na Tabela 1.

Tabela 1- Empresas das Aglomerações Produtivas do Setor de Tecnologia da Informação das Regiões Metropolitanas de Curitiba, Londrina e Maringá (PR), em relação ao Paraná, 2013

\begin{tabular}{|c|c|c|c|c|c|c|}
\hline \multicolumn{7}{|c|}{ EMPRESAS DE TECNOLOGIA DA INFORMAÇÃO } \\
\hline \multicolumn{3}{|c|}{ Número de Empresas } & \multicolumn{4}{|c|}{$\begin{array}{l}\text { Números de Empregados: } \\
\end{array}$} \\
\hline PORTE & $\begin{array}{c}\text { RMC, RML } \\
\text { e RMM }\end{array}$ & $\mathbf{P R}$ & $\begin{array}{c}\text { \% RMC, } \\
\text { RML e } \\
\text { RMM/PR }\end{array}$ & $\begin{array}{c}\text { RMC, RML } \\
\text { e RMM }\end{array}$ & $\mathbf{P R}$ & $\begin{array}{c}\text { \% RMC, } \\
\text { RML e } \\
\text { RMM/PR }\end{array}$ \\
\hline Micro & 961 & 1.174 & 81,85 & 8.427 & 10.556 & 79,75 \\
\hline Pequena & 67 & 71 & 94,36 & 1.855 & 2.334 & 79,47 \\
\hline Média & 20 & 21 & 95,23 & 1.541 & 1.603 & 96,13 \\
\hline Grande & 07 & 07 & 100,00 & 1.154 & 1.154 & 100,00 \\
\hline Total & 1.055 & 1.273 & 82,87 & 12.977 & 15.657 & 82,88 \\
\hline
\end{tabular}

Fontes: RAIS/CAGED, Ministério do Trabalho e Emprego (2011/12); APLs/PR - Seminários (2012);

ASSESPRO/PR (2013); FIEP (2013); e Pesquisa de Campo.

Em relação ao emprego, de acordo com a tabela 1, a aglomeração produtiva do setor de Tecnologia da Informação (TI) das regiões metropolitanas de Curitiba, Londrina e Maringá (PR) ocupa significativo destaque, com $82,88 \%$ dos postos de trabalho dessa indústria de TI em relação ao PR. A média de emprego dessa indústria para as RMC, RML e RMM, em relação ao agregado das três regiões, é da ordem de: 8,76 , para as micro; 27,68, para as pequenas; 77,05, para as médias; e, de 164,85 para as grandes empresas. Assim, MPMEs (Micro, Pequenas e Médias Empresas), ocupam significativos $91,10 \%$ dos postos de trabalho dessas aglomerações de firmas nessas regiões.

\section{Resultados e Discussão}

\subsection{Relações das Firmas com seu Mercado Consumidor - Fornecedor}

As empresas pesquisadas apresentaram em média oito anos de mercado, sendo que a RMC apresenta a mais jovem - com cinco anos de mercado - e duas das mais antigas, com trinta e cinco e trinta e sete anos. A RML destaca-se com três empresas com dez anos de atuação no mercado, três com dezesseis e uma com quarenta e três anos, a mais antiga entre as pesquisadas. A RMM apresenta a média intermediária das regiões, com três empresas de vinte dois anos de mercado. No agregado entre as mais maduras, cinco apresentam quinze anos de mercado, outras cinco vinte dois, quatro vinte seis anos e, finalmente, três com vinte e oito; conforme destaques da Figura 1.

\footnotetext{
${ }^{2}$ Classificação SEBRAE (Serviço Brasileiro de Apoio às Micro e Pequenas Empresas): Microempresa, até 20 funcionários; Pequena Empresa, de 21 a 50; Média Empresa, de 51 a 100; e Grande Empresa, acima de 100 funcionários.
} 
Figura 1- Média de Anos de Atuação no Mercado das Empresas Pesquisadas, das Aglomerações Produtivas de Tecnologia da Informação da RMC, RML e RMM, 2013

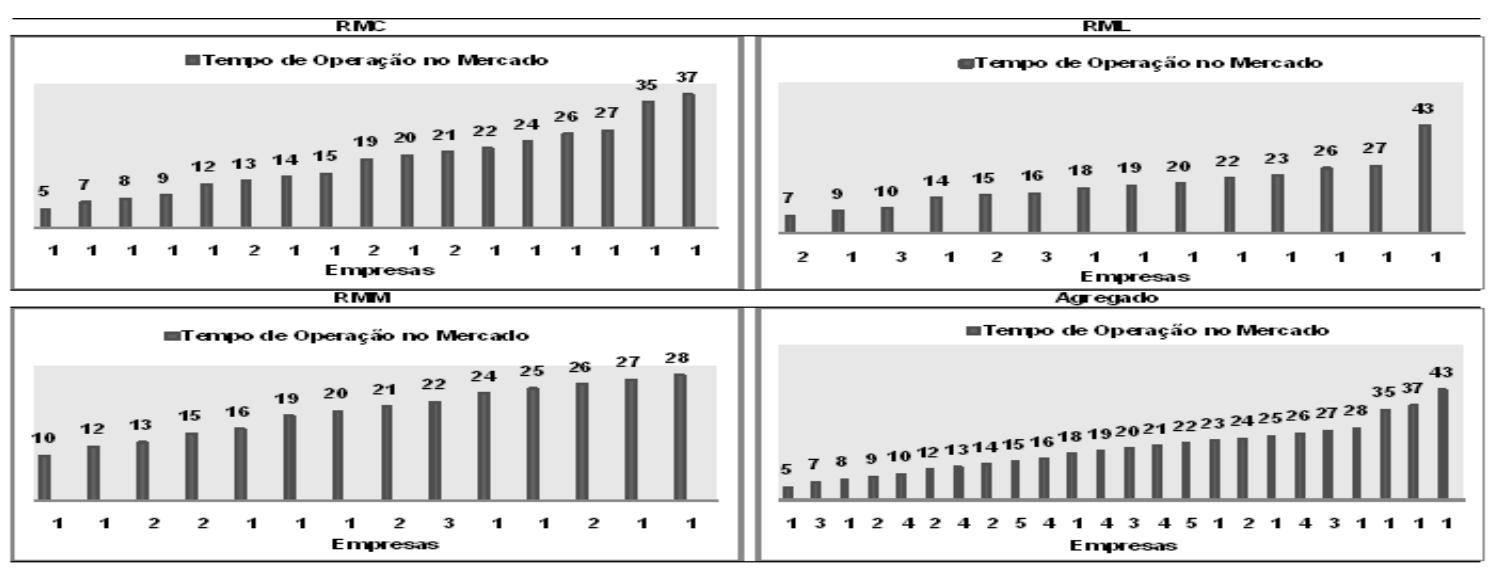

Fonte: Pesquisa de campo.

\subsection{Relações de Cooperação entre Firmas}

Os resultados da pesquisa sobre a organização do conjunto das empresas dessas aglomerações produtivas, acerca da cooperação para inovação de processos e produtos - conforme apresentado nas figuras 4 e 5 - dão conta de que a maioria das empresas pesquisadas considera relevante a cooperação entre elas. Em grande medida, essa cooperação se dá entre a própria empresa e outras do mesmo grupo empresarial, no nível de 69\% para o interior da RMC, de 44\% na RML e de 38\% para a RMM. O que se observa, entretanto, é uma maior intensificação da segunda e terceira regiões com a primeira, caracterizando os aspectos de seguimento de uma região pela outra. A pesquisa buscou identificar onde estão os colaboradores das firmas, as quais as auxiliam na construção e na geração de economias de externalidades.

A cooperação com empresas concorrentes - em interesses comuns - ganha destaque, relacionando-se no nível de 64\% para a RMC, 61\% para a RML e 52\% para a RMM. Em termos agregados, as inter-relações regionais destacam-se com 30,3\% para a RMC, 27,7\% para a RML e 23,3\% para a RM. Tais relações são intermediadas por entidades como a ASSESPRO/PR e outras de coordenação e apoio (diversas), destacadas por 44 das 60 empresas pesquisadas (73\% da amostra), como a FIEP, o SEBRAE e os Centros de Coordenação dos APLs de TI, com reduzidas iniciativas partindo das próprias empresas. Essas relações, em grande medida, configuram-se por meio das relações de subcontratações presentes nas aglomerações de TI.

Quanto à cooperação com consumidores de seus produtos, destacada no terceiro segmento, 27 empresas (45\% da amostra) apresentaram produtos confeccionados a partir de sugestões de clientes, como é o caso da indústria de TI. Nesse segmento, a RMM se sobressai com $51 \%$ das relações intrarregião, a RML, com 49\%, e a RMC, com 45\%. No nível agregado, as médias das relações apresentam a RMC com 26,3\%, a RML com $23,4 \%$ e a RMM com $24 \%$ das relações com consumidores. Nesse segmento, quanto mais diversificada é a atuação da região em produtos e serviços, maior tende a ser o volume de cooperação intrarregião, uma vez que a segunda e terceira regiões, nesse segmento, apresentam maior expansão em relação aos serviços básicos em TI. Essa forma de cooperação está mais presente nas empresas com maior tempo de mercado e com maior amadurecimento de relacionamento com o consumidor, sendo que ambos - consumidores e produtores - podem ser importantes empresas "parceiras" próximas da fronteira de seu setor.

As informações coletadas, conforme apresentadas na Figura 4, mostram que um significativo número de colaboradores está presente na RMC, RML e RMM, bem como a cooperação com o SEBRAE é a que mais se destaca ao nível destas aglomerações de firmas. A RMC apresenta importante inter-relação de cooperação intrarregional com o SEBRAE no nível de 79\%, a RML, no nível de 71\%; e a RMM, 66\%. No nível agregado, a RMC destaca-se com 34,7\%. Vale ressaltar, ainda, a importância dessa instituição da capital nas relações interregionais com a segunda e terceira 
região. A RML, na esfera agregada, destaca-se com 29,7\%; e a RMM com 26,6\%. Ao lado do núcleo gestor dos APLs, o SEBRAE é a entidade de apoio mais lembrada pelos empresários.

Em relação à cooperação com os núcleos gestores regionais de APLs, a RMC possui maior cooperação intrarregional, com nível de $78 \%$, caracterizando sua maior maturidade nesse segmento. A RML possui inter-relações de cooperação no nível de $72 \%$ e a RMM, com nível de $65 \%$. Notadamente para a segunda e a terceira regiões são importantes as relações de cooperação com o núcleo gestor da RMC. No nível agregado, a RMC se sobressai com 36,3\%, a RML com 28,5\% e a RMM com 24,6\%. Os núcleos gestores em APLs apresentam significativa evolução para a RMC, posto que essa região apresenta maior maturidade e iniciativas de cooperação frente à segunda e à terceira.

Figura 4- Localização dos Parceiros das Empresas do Arranjo de Tecnologia da Informação da RMC, RML e RMM, em percentuais, 2013

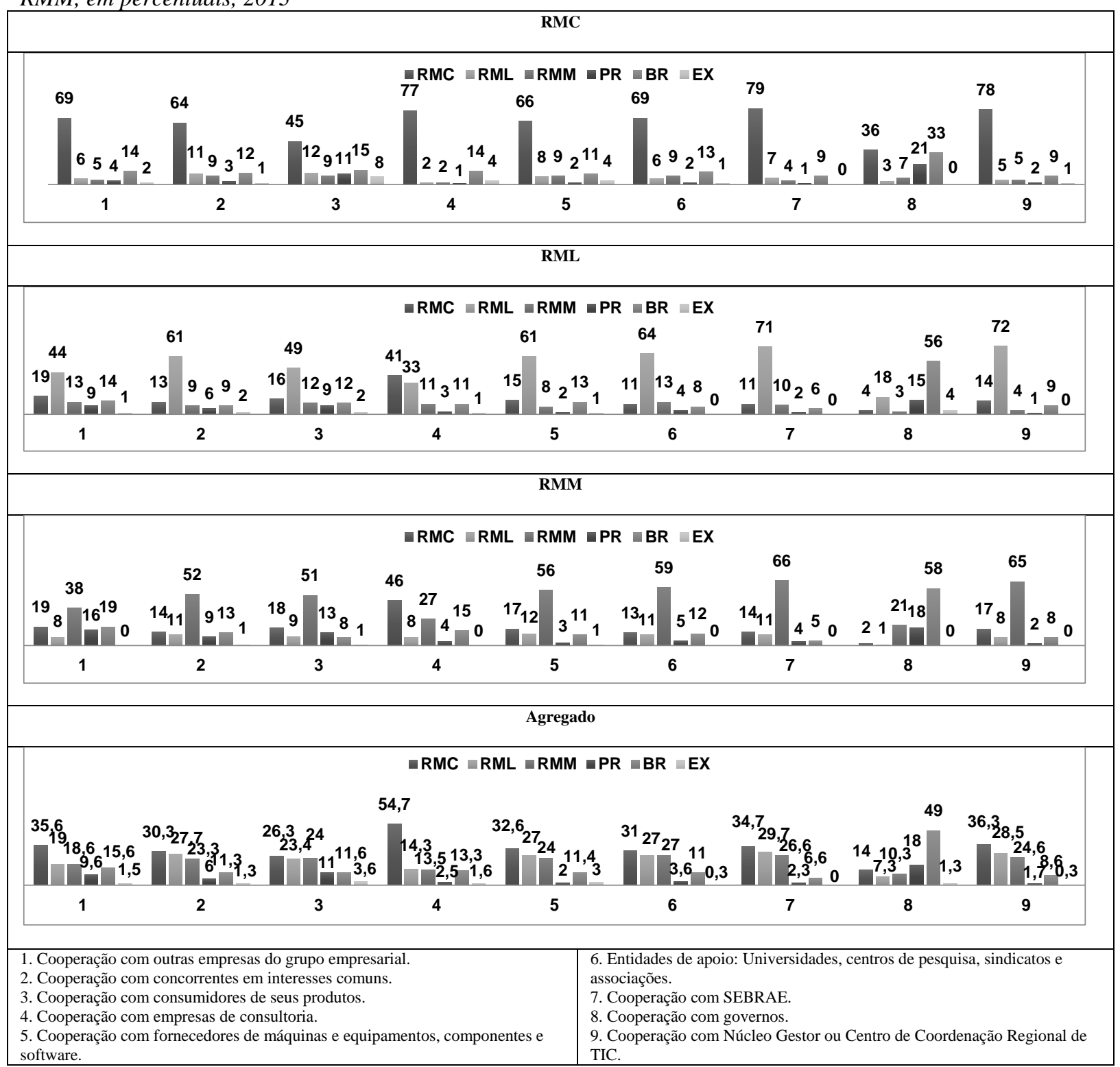

\section{Fonte: Pesquisa de campo.}

Para as empresas pesquisadas as formas de cooperação mais utilizadas numa indicação de ordem de alta, baixa e média, ao buscarem-se as indicações mais importantes para a articulação da cooperação inovativa, as de mais alta significância, conforme apresenta a Figura 5, foram as seguintes. A cooperação com agências governamentais é a mais importante forma utilizada pelas empresas, com forte relevância para a RMC,com nível de $45 \%$ (nove empresas), enquanto as demais regiões utilizam esse segmento com média relevância, com 10 indicações para a RML (50\%) e nove indicações para a 
RMM (45\%). Por exemplo, as empresas vêm conquistando apoio para eventos, financiamentos de pesquisas e na RMC e RML com espaços para ampliação e novas instalações industriais.

$\mathrm{O}$ intercâmbio com pesquisadores, de acordo com as respostas das empresas, apresenta maior expressão na primeira e segunda regiões, com indicações de alta cooperação em níveis de $70 \%$ (14 empresas). Na RMM, sobressaem-se os índices de baixa cooperação, indicadas por 55\% (11 empresas). Em termos agregados, esses segmentos têm alta importância, de 48\% (29 empresas), caracterizando importante relação de cooperação das empresas com os pesquisadores desse setor, presente nas universidades paranaenses.

Figura 5- Formas de Cooperação mais Utilizadas, Indicadas pelas Empresas do Arranjo de Tecnologia da Informação da RMC, RML e RMM, 2013

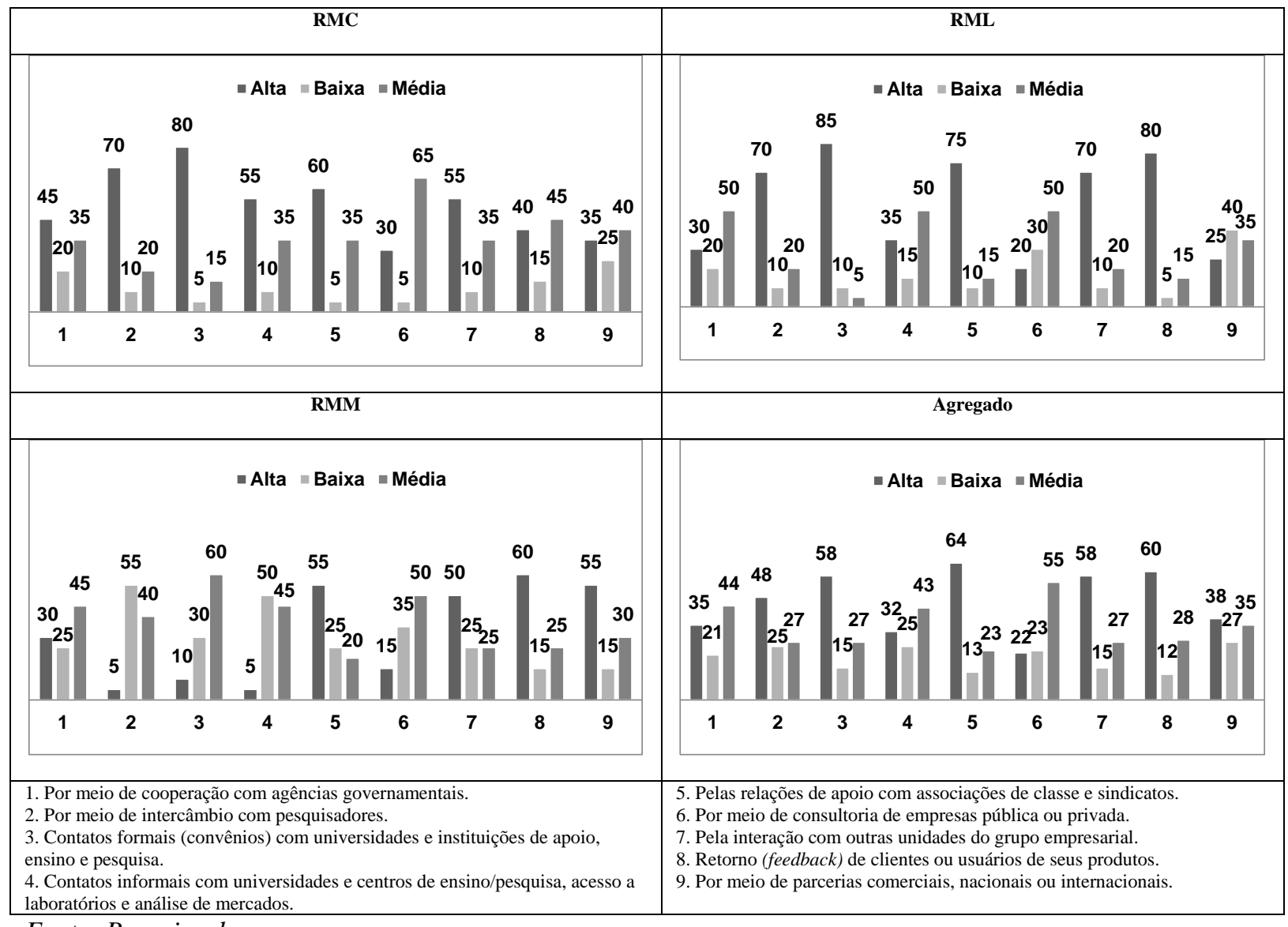

Fonte: Pesquisa de campo.

Esse conjunto de relações mostra aglomerações produtivas que aos poucos constroem suas ligações de cooperação. As pequenas empresas, correspondendo a 38, e a $63 \%$ da amostra, são as que mais se destacam na articulação entre elas e com as demais empresas presentes. A pesquisa também identificou forte competição entre empresas, visto que das pequenas, presentes nessas aglomerações de firmas, quatro foram incorporadas por outras, com a finalidade de melhorar seu poder competitivo e ampliar sua importância individual no contexto das demais. Entre as grandes empresas, as dificuldades de cooperação são maiores, visto que possuem uma estrutura mais rígida. Das três grandes empresas presentes, uma se destacou nas relações de cooperação com os Centros de Coordenação em TI e universidades, tendo apresentado resultados de melhoria técnica e organizacional em parceria com essas instituições. Essa empresa ocupa relativa posição de liderança e pode redirecionar as demais em projetos de ações conjuntas.

Em relação às inovações de produtos, conforme apresenta a Figura 6, a pesquisa apresentou uma forte concentração de respostas, verificada num total de 18 das 20 firmas pesquisadas na RMC $90 \%$ - destacando inovações implementadas a partir da realização de melhoria na visibilidade e apresentação dos produtos, alterações no desenho, na cor, na forma ou estilo dos produtos. Nesse 
sentido, a RMM destacou-se com 85\% (17 empresas) e a RML com 80\% (16 empresas). Em relação à incorporação de apropriabilidades e novas funções aos produtos, a RMC e a RML destacam-se igualmente com 95\% (19 empresas) e a RMM apresenta 90\% (18 empresas). Isto pode ser interpretado como sinal de que as firmas vêm buscando seguir o nível tecnológico apresentado em aplicativos e ofertando novas opções de recursos tecnológicos aos clientes.

Os dados absolutos das citações de inovações de processos, reunidos na figura 6, são importantes para a ampliação da capacidade de produção e competição das firmas no mercado. Essas ações desenvolvidas pelas empresas ampliam suas condições de apropriabilidade e cumulatividade, e tendem a incorporar novos padrões em suas rotinas de atividades inovativas. As ampliações na planta industrial aparecem em maior destaque, em igual proporção de 75\% (15 empresas) para a RMC e para a RML; $70 \%$ para a RMM (14 empresas); e, no agregado, com 73,3\%, o que representa 44 das 60 empresas dessa amostra. Em relação à construção de nova planta industrial, a região de formação mais recente, a RMM, tende a se sobressair, com 35\% (7 empresas); a RMC com 30\% (6 empresas), a RML com $25 \%$ (5 empresas); e o agregado com $30 \%$, correspondente a 18 empresas do total pesquisado. Neste setor, o destaque é para as micro e pequenas empresas. Em termos de rearranjo organizacional no interior das empresas, esse segmento ganha destaque com 95\% na RMC (19 empresas). Essa é a região que mais cresce em TI no PR. Para a RML esse dado é de 90\% (18 empresas), enquanto na RMM é de $85 \%$. A média agregada fica em $90 \%$, equivalente a 54 firmas. Em geral, as empresas precisam ampliar seu volume de colaboradores, utilizando-se de um mesmo espaço físico de sua planta industrial.

Figura 6- Inovações de Processo e de Produtos, em Número de Citações nas Firmas das Aglomerações Produtivas de TI das RMC, RML e RMM, em Percentuais, entre 2006 e 2012

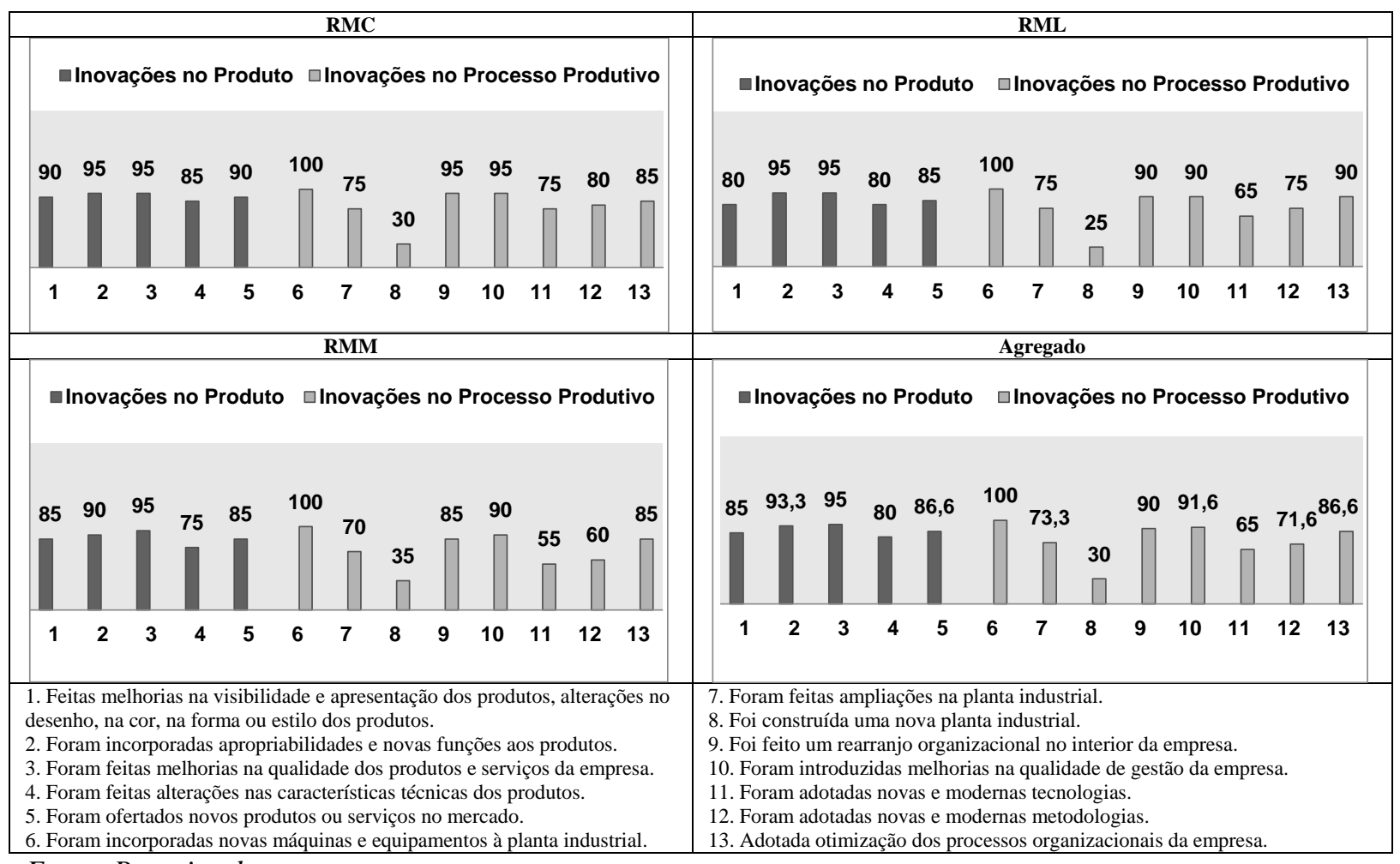

Fonte: Pesquisa de campo.

A busca de aperfeiçoamento desses segmentos inovativos reflete os ganhos de competição mercadológica e tecnológica auferidos por essas firmas, por força das inovações anteriormente destacadas. Isso revela uma atmosfera positiva presente nessa atividade, nessas aglomerações produtivas, em Tecnologia da Informação, das RMC, RML e RMM. A presença na utilização das novas metodologias e tecnologias, bem como nas ampliações de planta industrial, e, na regular idade média das máquinas, verificada neste estudo de caso, é inferior à idade dessa indústria local regional (13 meses) de Tecnologia da Informação, frente ao nível nacional (15 meses). Indica que as 


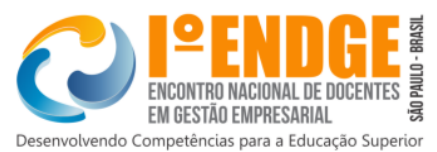

aglomerações produtivas dessas regiões encontram-se em uma posição relativamente próxima de sua fronteira tecnológica, com destaques para a RMC, a qual é impulsionada pelos seguintes fatores de inovação: adesão de inovações em M\&E (Máquinas e Equipamentos) compatível com a média de seu setor ao nível nacional, adesão aos modelos de maturidade para a Melhoria de Qualidade de Software (MQS), por meio das diversas certificações, como o MPS.Br e o CMMI pelas empresas líderes dessas aglomerações produtivas,e a ampliação de suas plantas industriais.

\subsection{Relações de Cooperação Empresas-Instituições para Busca da Inovação}

Com essa perspectiva, foram entrevistadas 23 instituições de coordenação e apoio destacadas nas inter-relações desse nível meso, desde aquelas voltadas unicamente às aglomerações de Tecnologia de Informação, como é o caso dos Centros de Coordenação Regional de TIC, do SEBRAE e da ASSESPRO/PR, até as demais, as quais também possuem ligações com outras indústrias, como as instituições de ensino - CEFET-PR, UFPR, UEM, UEL, PUC/PR, Unifil - por meio de seu Departamento de Tecnologia de Informação e do Departamento de Gestão e Administração (consultorias) - SENAI e CEFET-PR e as de apoio e complemento à qualificação técnica e empresarial, como o SEBRAE, FIEP, AMPROTEC e NEXTI.

As interações nas ligações de cooperação empresas-instituições de apoio estão particularmente marcadas pelas primeiras mais importantes instituições - conforme apresenta a Figura 7, por meio da importância de seu nível de relacionamento, as quais têm a missão de responder, positivamente, às ações de coordenação e orientação às empresas integrantes dessas aglomerações de Tecnologia da Informação da RMC, RML e RMM, que mensal, semestral, ou anualmente, procuram as instituições. Todas as empresas mantêm certo nível de relacionamento cooperativo com alguma entidade aqui relacionada, sendo que a posição desse nível depende da classificação dada pelas empresas, se alta, média ou baixa.

Para a RMC, a primeira entidade que apresenta significativo nível de relacionamento cooperativo com as empresas é o CITS/PR. Este dispõe de um conjunto próprio de empresas de tecnologia da informação, com avançadas qualificações técnicas em TI, com melhoramentos e geração de novos produtos, com poder de exercer forte influência sobre as demais empresas das três regiões. $\mathrm{Na} \mathrm{RMC}$, a pesquisa apontou para uma alta intensidade de relacionamento, no nível de $88 \%$. O CITS/PR também é importante para a RML, devido algumas empresas que atuam no mercado londrinense serem filiais de empresas integrantes do CITS/PR. Logo, este é um importante referencial para as empresas dessa aglomeração produtiva, no nível de $88 \%$, sendo destacado por 18 delas nessa aglomeração. O CITS/PR, em relação à esfera agregada, mantém importantes ligações de cooperação, apontadas por $72 \%$ do total das empresas pesquisadas nas três regiões, equivalendo a 43 empresas do conjunto da amostra.

Para a RML, a primeira entidade a apresentar alto nível de relacionamento e cooperação é a UEL, por meio de seu importante trabalho de qualificação técnica da mão-de-obra local, em áreas relacionadas à Tecnologia da Informação, desde a graduação até a pós-graduação, sendo lembrada nessa aglomeração produtiva por 95\% (19 empresas). Por meio de sua incubadora tecnológica (INTEC), desde 17 de abril de 2008, funciona inserida na estrutura organizacional da UEL, como uma entidade parceira na promoção da inovação ao setor produtivo, estimulando a geração de empresas de base tecnológica, contando, atualmente, com 14 delas atuantes no setor de TI. Além disso, tem sido importante na cooperação com as empresas, ao gerar conhecimentos que são apropriados por elas e, ao mesmo tempo, funciona com seu corpo diretivo no sentido de orientá-las, ao prestar assessoria técnica às empresas do setor de TI.

Para a RMM, a primeira entidade a apresentar alto nível de relacionamento e cooperação é o SEBRAE/PR, por meio de sua ampla articulação e coordenação das empresas das três regiões, na busca de objetivos comuns, para a melhoria competitiva do setor e atuação tecnológica e mercadológica na esfera nacional e internacional, tendo importantes níveis de relacionamento, sendo de $82,5 \%$ para a RMC e de $85,5 \%$ para a RML. O SEBRAE tem se mostrado nesta última região, ao lado da coordenação da APL de TI de Londrina, o principal articulador das ações de indução de desenvolvimento e coordenação junto a essa aglomeração produtiva. O índice é de $81 \%$ para a RMM região, assumindo uma posição de principal agente coordenador nessa região ao lado do SOFTWARE by Maringá. Na esfera agregada, o SEBRAE/PR atua por meio de sua ampla articulação e coordenação 


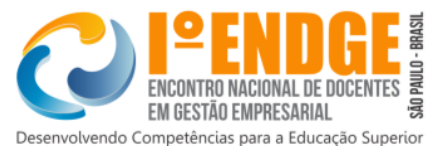

das empresas de TI, na busca de objetivos comuns para a melhoria competitiva do setor, ao marcar presença nas ligações de cooperação em $85,5 \%$ dos casos equivale a 51 empresas do total da amostra.

Figura 7- Ligações de Cooperação, das Empresas, com as Instituições de Apoio e Coordenação Presentes no Arranjo de TI da RMC, RML e RMM, conforme o Nivel de Relacionamento, 2013

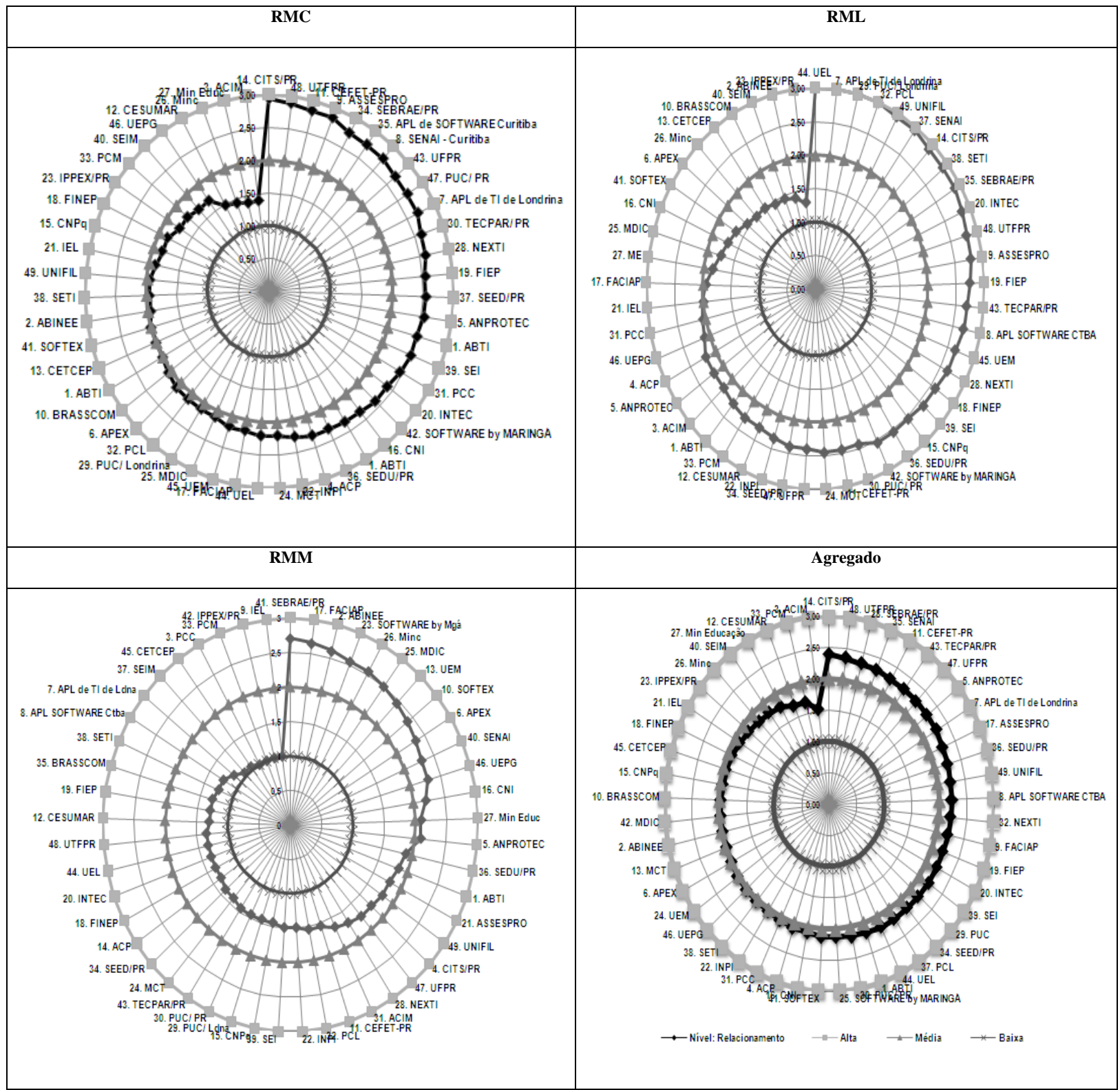

Fonte: Pesquisa de campo.

No agregado, além das que já foram destacadas, está outra relevante instituição, com relevantes ligações de cooperação para as três regiões: o TECPAR/PR, uma importante empresa do setor de TI, atuante na área médica, ligada à Secretaria de Ensino Superior do Paraná, a qual abriga a Incubadora Tecnológica de Curitiba (INTEC) e possui centros de ensaios tecnológicos em áreas como biocombustíveis, microbiologia, toxicologia, agroquímica, biologia molecular humana e animal e de inteligência artificial. O TECPAR ainda está credenciado pelo Inmetro a conceder certificações a sistemas, produtos, processos e serviços, permitindo o uso da marca TecparCert. 


\section{Considerações Finais}

Este trabalho teve como objetivo caracterizar a estrutura produtiva recente da aglomeração produtiva de Tecnologia da Informação das Regiões Metropolitanas de Curitiba, Londrina e Maringá/PR em seu nível meso. A pesquisa observou uma média colaboração para ações conjuntas, ficando as mesmas tomadas no âmbito da melhoria da qualificação técnica, notadamente por meio de articulações entre as empresas e entidades de apoio e coordenação como o SEBRAE/PR, ASSESPRO e SENAI. No nível das organizações de feiras, os Centros de Coordenação de APLs, com apoio de entidades como a SOFTEX, ANPROTEC e dos órgãos públicos como a SEIM (Secretaria de Indústria, Comércio e Assuntos do MERCOSUL) e das prefeituras de Curitiba, Londrina e Maringá.

Em relação às Universidades, essas têm participado em colaboração com os Centros de Coordenação de APLs por meio de seus diversos departamentos, principalmente na melhoria da qualificação gerencial das empresas e da qualidade e padronização para posterior certificação. As entidades e associações de apoio foram as que mais estabeleceram relações de ligações com as empresas. Estas refletem o importante impacto que as associações e entidades de apoio exercem junto às empresas dessas aglomerações produtivas. Embora a pesquisa tenha apontado para uma comunidade de baixa a média identidade sócio-cultural, o desejo das empresas de melhorar suas condições de competência, por meio de um relacionamento ganha-ganha - destacado por algumas empresas e entidades entrevistadas- facilita a cooperação, a solidariedade, a reciprocidade e o intercâmbio entre os agentes fornecedores-produtores-consumidores.

O objetivo da pesquisa não foi a proposição de medidas, mas os dados mostram que há deficiências e necessidades que requerem ações de urgência e melhoria continuada, a fim de se consolidar uma integração dessas aglomerações produtivas de Tecnologia da Informação das RMC, RML e RMM. Por exemplo: treinar e fortalecer a eficiência coletiva; melhorar a estrutura organizacional com atribuições e tarefas bem definidas entre os atores presentes; participar de feiras diversas; articular uma estrutura de empresas desse setor para exportações por meio de regras bem definidas; e, finalmente, intensificar as ações de especialização das firmas, por meio de certificações em seus diversos níveis. Assim, observou-se que o principal fator determinante da busca da formação da competência pela eficiência coletiva está fortemente amparado nas relações de cooperação entre firmas, com entidades de apoio e através das coordenações público/privadas.

\section{Referências bibliográficas}

APLs/PR - Seminários, (2012/2013). ParanáIT, Ibusiness. Encontros de discussões do setor de Tecnologia da Informação no Paraná.

ASSESPRO/PR - Associação das Empresas de TI do PR. Curitiba/PR, Pesquisa de Campo.

ASSESPRO. Perspectivas e déficit de trabalhadores no setor de TIC brasileiro. Disponível em: <http://www.assespropr.org.br>. Acesso em: 11/02/2013.

BECATTINI, G. O distrito marshalliano. In: BENKO, G.; LIPIETZ, A. As regiões ganhadoras. Oeiras: Celta Editora, 1994, p. 19-31.

BIANCHI, P.; TOMMASO, M. R. Política industrial para las PYME en la economía global. Comércio Exterior, v.48, n.8, agosto, 1998, p. 617-623.

CAMPOS, A.C. Arranjos Produtivos no Estado do Paraná: o caso do município de Cianorte. Curitiba/UFPR, 2004. (218 p. Tese de Doutorado em Ciências Econômicas).

CIMOLI, M.; DELLAGIUSTA, M. The nature of technological change and its main implications on national and local systems of innovation. International Institute for Applied Systems Analysis (IIASA), Interin Report, n. 28, p. 53, jun. 1998.

EDQUIST, C. (Ed.). Systems of innovation, Pinter, London and Washington, 1997.

FIEP - FEDERAÇÃO DAS INDÚSTRIAS DO ESTADO DO PARANÁ. Curitiba/PR. Pesquisa de Campo. 
Relatório da Economia Paranaense, Dados Setoriais. Disponível em:

<www.fiepr.org.br/observatorios/bussoladainovacao〉. Acesso em 05/03/2013.

GAROFOLI, G. Os sistemas de pequenas empresas. In: BENKO, G.; LIPIETZ, A. As regiões ganhadoras. Oeiras: Celta Editora, 1994, p. 33 - 47.

MARSHALL, A. Princípios de economia: tratado introdutório. São Paulo: Nova Cultural, 1996.

MINISTÉRIO DO TRABALHO E EMPREGO. RAIS - Relação Anual de Informações Sociais. Brasília: Ministério do Trabalho e CAGED, 2011/12. CD ROM. Pesquisa da evolução empresarial e empregatícia de Tecnologia da Informação e Comunicação.

SCHMITZ, H. Eficiência coletiva: caminho do crescimento para a indústria de pequeno porte. Ensaios FEE, v. 18, n.2, 1997, p. 164-200.

SEBRAE - SERVIÇO BRASILEIRO DE APOIO ÀS MICRO E PEQUENAS EMPRESAS, PARANÁ. Curitiba/PR, 2013. Pesquisa de Campo.

SEIM - Secretaria de Indústria, Comércio e Assuntos do MERCOSUL. Curitiba/PR, Pesquisa de Campo.

SENAI - SERVIÇO NACIONAL DE APRENDIZAGEM INDUSTRIAL. Curitiba/PR, Pesquisa de Campo. 